\title{
Alternate Technique for Doing Laparoscopic Cholecystectomy in Situs Inversus"
}

\author{
Vikrant Singh $^{1}$, Zahur Hussain ${ }^{1}$, Shadilal Kachroo ${ }^{1}$, Vanita Gupta ${ }^{2 \#}$, Harbinder Singh ${ }^{1}$, \\ Mukesh Kumar ${ }^{1}$, Barinder Kumar ${ }^{1}$ \\ ${ }^{1}$ Government Medical College, Jammu, India \\ ${ }^{2}$ Acharya Shree Chander College of Medical Sciences, Jammu, India \\ Email: vikrant1118@rediffmail.com, "doctorvanita@yahoo.co.in
}

Received May 3, 2013; revised June 2, 2013; accepted June 10, 2013

Copyright (C) 2013 Vikrant Singh et al. This is an open access article distributed under the Creative Commons Attribution License, which permits unrestricted use, distribution, and reproduction in any medium, provided the original work is properly cited.

\begin{abstract}
A 45-year-old female with known situs inversus totalis presented with left-sided abdominal discomfort. Chest X-ray, abdominal ultrasonography and CT scan confirmed the diagnosis of a gallstone, as well as, situs inversus; Laparoscopic cholecystectomy was safely performed with mirror image of standard 4 ports. Callots triangle dissection was done with epigastric working port by surgeon, but gallbladder fossa dissection was done by surgical assistant from midclavicular port as main working port. Laparoscopic surgeon should be careful for view of reversed relationships and also for existence of other anomalies.
\end{abstract}

Keywords: Situs Inversus Totalis; Laparoscopic Cholecystectomy; Anomalies

\section{Introduction}

Situs inversus is a morphological anomaly of positioning of internal viscera wherein there is a reversal of the usual "handedness" of visceral topography. The reversal may be thoracic, abdominal or both. It is estimated to occur in 1 in 5000 - 20,000 births [1,2]. In the published literature, there have been only about 40 reports of open cholecystectomy in the pre-laparoscopic era and 20 reports of laparoscopic cholecystectomy in patients with situs inversus [2-4]. Although there are many reports of patients with situs inversus and cholelithiasis, there is no evidence that the incidence of cholelithiasis is greater in these patients [5]. It has been reported that about a third of patients with situs inversus and symptomatic gall stones may, however, present with epigastric pain and about $10 \%$ of patients may present with right-sided pain [6].

\section{Case Report}

Our patient was a 45-year-old female patient, who had four children. Patient presented with pain left side of abdomen and was been treated with antibiotics and painkillers with no relief, after which ultrasound was done which re-

\footnotetext{
*The work was conducted in Department of Surgery, Government Medical College Jammu, J \& K.

\#Corresponding author.
}

vealed left sided gallbladder with stones in it. Patient had no co-morbidities or anomalies.

Chest X-ray showed dextrocardia consistent with situs inversus but there was no evidence of Bronchiectasis (Figure 1).

CECT showed situs inversus with Cholelithiasis (Figure 2).

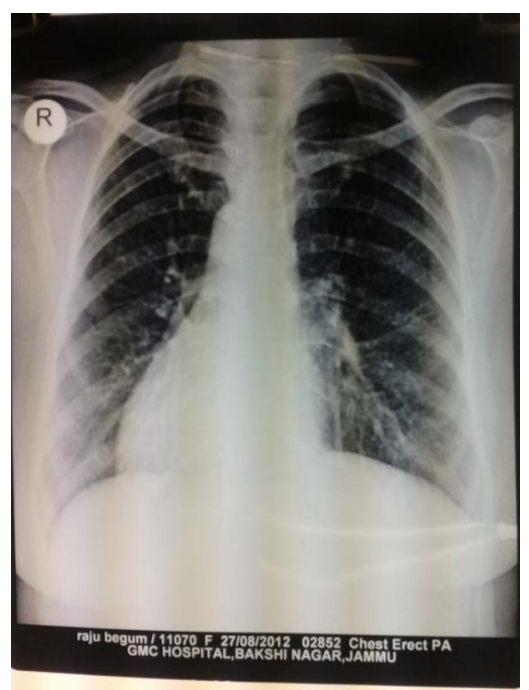

Figure 1. Chest X-ray showing dextrocardia consistent with situs inversus. 
Echo revealed dextrocardia with grade 1 diastolic dysfunction.

MRCP revealed situs inversus with Cholelithiasis (Figure 3).

The surgical procedure was modified according to our comfort. The surgeon and the camera man were positioned on the right side of the patient. An assistant and the scrub nurse were positioned on the left side (Figure 4). The video monitor was placed on the head end of patient. Standard 4-port mirror image technique was used -an umbilical $(10 \mathrm{~mm})$, epigastric $(10 \mathrm{~mm})$ and two subcostal $(5 \mathrm{~mm})$ ports. Pneumoperitoneum was established by open technique. $10 \mathrm{~mm}$ camera port was inserted. A head-end-up and left-side-up positioning of the patient was adopted to optimize views of the gall bladder and the Callot's triangle. The epigastric port $(10 \mathrm{~mm})$ was placed just to the left of the falciform ligament. This port was one of the two main operating ports and the instruments used were controlled by the right hand of the surgeon. It was used for dissection of callots triangle. The medial subcostal port was used for retraction of the Hartmann's pouch of the gall bladder initially and later for gallbladder bed dissection. The lateral subcostal port was used for fundal traction.

Diagnostic laparoscopy revealed a total situs inversus with left-sided liver and gall bladder, greater curvature and cecum. The organs on right side included spleen and the greater curve of the stomach (Figure 5).

Surgery was started with fundal retraction through lateral subcostal port, Hartmann's pouch retraction was done with medial subcostal port, and Callot's triangle dissection was done with epigastric port. Cystic artery and cystic duct were identified after dissection and clipped separately. After clipping cystic duct and cystic artery epigastric port was used as retraction port and medial subcostal port was used as dissecting port. This switching

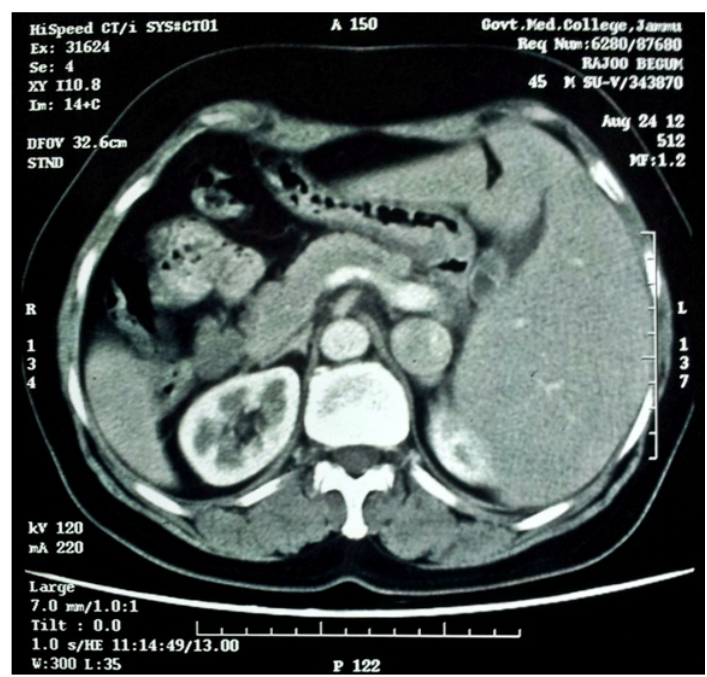

Figure 2. CECT showed situs inversus with cholelithiasis.

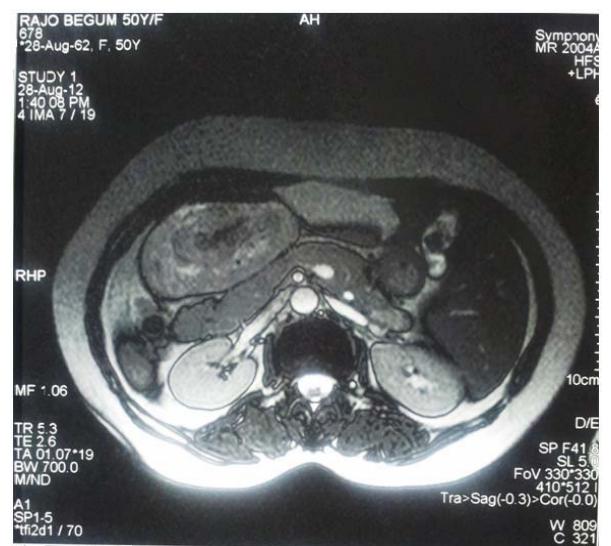

Figure 3. MRCP revealed situs inversus with cholelithiasis.

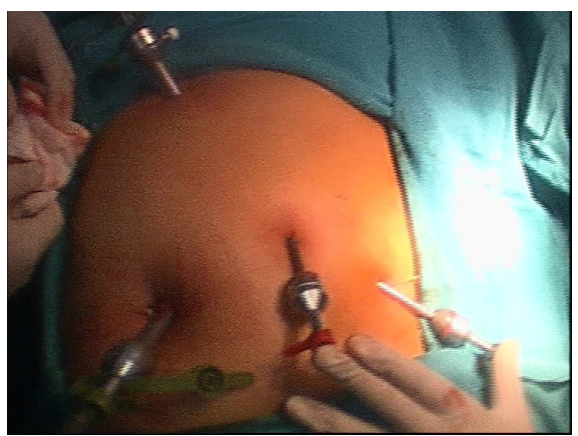

Figure 4. Port placements in situs inversus patient for laparoscopic cholecystectomy.

of dissecting port facilitated easy and smooth dissection of gallbladder from the gallbladder fossa. The gall bladder bed dissection was done by the surgeon who was assisting the case and standing on left side of patient. Our total operative time was 90 minutes.

\section{Discussion}

The cause of the situs inversus is unknown, but it is claimed to be due to a genetic predisposition, with an autosomal recessive transmission [2,4]. Drover et al. reported the first case to have laparoscopic cholecystectomy with this type of anomaly. Literature reveals very few reports of anomalies of biliary system especially in situs inversus totalis like that of Kamitani et al. who reported aberrant cystic artery running inferior to cystic duct [7]. Fabricus in 1600 reported first human case of situs inversus. Situs inversus may be total including abdominal and thoracic viscera (situs inversus totalis), or, more rarely, partial (situs inversus partialis). The transposition of the organs may be associated with other congenital anomalies, such as renal dysplasia, biliary atresia, congenital heart disease, or pancreatic fibrosis. Situs inversus totalis associated with bronchitis, chronic sinusitis, and deficient tracheobronchial cilia is known as the Kartagener's syndrome [8,9]. Table 1 has been made 
Table 1. The literature on cholecystectomy in patients of situs inversus.

\begin{tabular}{|c|c|c|c|c|}
\hline S. No & Author & Journal & Year & Ref. No \\
\hline 1 & Campos L et al. & J Laparoendosc Surg 1991(1):123-125 & 1991 & 1 \\
\hline 2 & Lipschutz JH et al. & Am J Gastroenterol 1992 87:218-220 & 1992 & 1 \\
\hline 3 & Takei HT et al. & J Laparoendosc Surg1992:2:171-176 & 1992 & 1 \\
\hline 4 & Drover JW et al. & Can J Surg 1992:35:65-66 & 1992 & 1 \\
\hline 5 & Huang SM et al. & Endoscopy 1992: 24:802 & 1992 & 1 \\
\hline 6 & Goh P et al. & Endoscopy 1992:24:799-800 & 1992 & 1 \\
\hline 7 & Schiffino L et al. & Minerva Chir 1993:48:1019-1023 & 1993 & 1 \\
\hline 8 & Mc Dermott JP et al. & Surg Endosc 1994:8:1227 & 1994 & 1 \\
\hline 9 & Idu M et al. & Br J Surg 1996 83:1442 & 1996 & 1 \\
\hline 10 & Grosher RF et al. & Jr Coll Surg Edinb 1996:41:183 & 1996 & 1 \\
\hline 11 & D Agata A et al. & Minerva Chir 1997:52:271-275 & 1997 & 1 \\
\hline 12 & Habib Z et al. & Ann Saudi Med 1998:247-248 & 1998 & 1 \\
\hline 13 & Demetriades $\mathrm{H}$ et al. & Dig Surg 1999: 16 (6):519-521 & 1999 & 1 \\
\hline 14 & Djohan RS et al. & JSLS 2000:4:251-254 & 2000 & 1 \\
\hline 15 & Yaghan RJ et al. & J Laparoendosc Adv Surg Tech A 2001:11(4):233-237 & 2001 & 1 \\
\hline 16 & Nursal TZ et al. & J Laparoendosc Adv Surg Tech A 2001:11 & 2001 & 1 \\
\hline 17 & Al-Jumaily M et al. & J Laparoendosc Adv Surg Tech A 2001:11 & 2001 & 1 \\
\hline 18 & Wong $\mathrm{J}$ et al. & Surg Endosc 2001:15:254 & 2001 & 1 \\
\hline 19 & Polychronides A et al. & Surg Endosc 2002:16(7):1110 & 2002 & 1 \\
\hline 20 & Singh K et al. & Surg Techno Lint 2002:10:107-108 & 2002 & 1 \\
\hline 21 & Oms LM et al. & Surg Endosc 2003:17:1859-1861 & 2003 & 1 \\
\hline 22 & Kang B et al. & J Laparoendosc Adv Surg Tech A 2004:14(2):103-106 & 2004 & 1 \\
\hline 23 & Docimog et al. & Hepatogastroentrology 2004:958-960 & 2004 & 1 \\
\hline 24 & Antal A et al. & Magy Seb 2004:81-83 & 2004 & 1 \\
\hline 25 & Pitiakoudis M et al. & Acta Chir Belg 2005:11 105 (1):1114-117 & 2005 & 1 \\
\hline 26 & Mc Kay D et al. & Bmc Surg 2005:5-5 & 2005 & 1 \\
\hline 27 & Kamitani S et al. & World J Gastroenterol 2005:11 (33):5232:5234 & 2005 & 1 \\
\hline 28 & Puglisi F et al. & Chir Ital 2006:58(2):179-183 & 2006 & 1 \\
\hline 29 & Bedioui H et al. & Ann Chir 2006:131(6-7):398-400 & 2006 & 1 \\
\hline 30 & Machado No et al. & Jsls 2006: 10(3):386-391 & 2006 & 1 \\
\hline 31 & Aydin U et al. & World J Gastroenterol 2006:21:12(47):7717-7719 & 2006 & 1 \\
\hline 32 & Kirsteinb et al. & Surg Lap Endosc Perc Techn 2006:169-171 & 2006 & 1 \\
\hline 33 & Kumar S et al. & Ann R C S Engl 2007:89(2):W 16-18 & 2007 & 1 \\
\hline 34 & Pavlides TH et al. & Diagn Ther Endosc 2008:46:52-72 & 2008 & 1 \\
\hline 35 & Hamdi J et al. & Saudi J Gastroenterology 2008:14(1):31-32 & 2008 & 1 \\
\hline 36 & Garcia-Nunez L et al. & Rev Gastroenterol Mex 2008:73(3):149-152 & 2008 & 1 \\
\hline 37 & Pereira-Graterol F et al. & Cir Cir 2009:77(2):145-148 & 2009 & 1 \\
\hline 38 & Romano GG et al. & G Cir 2009:30(8-9):369-373 & 2009 & 1 \\
\hline
\end{tabular}




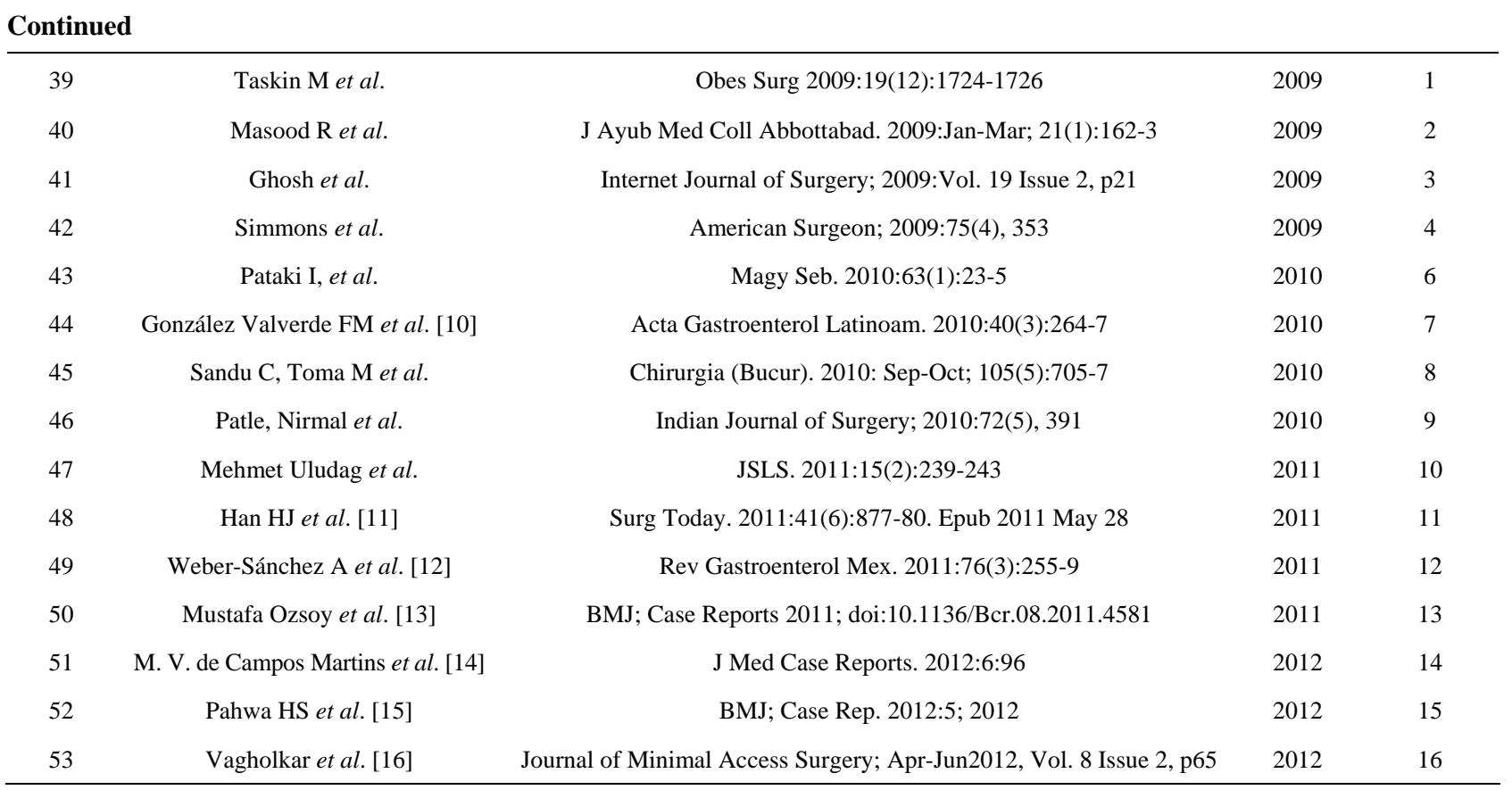

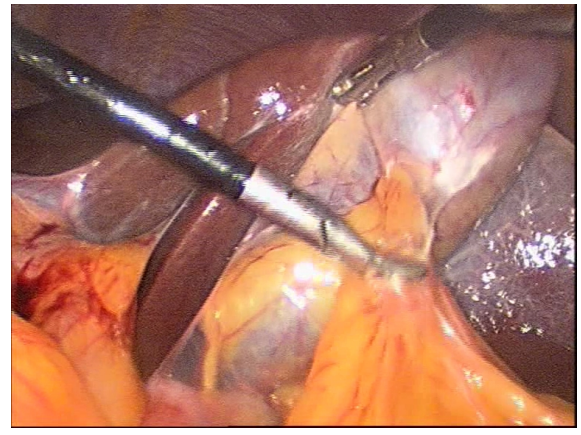

Figure 5. Laparoscopic picture of gall bladder in patient of situs inversus.

after thorough search from internet which revealed 53 published cases of cholecystectomy in situs inversus.

\section{Conclusions}

Asymptomatic or undiagnosed situs inversus with symptomatic gall stone provides a diagnostic dilemma for clinician as the symptoms are predominantly on the left side.

The principles of surgery are the same except for slight modification of port placement.

Switching the dissecting port from epigastric to medial subcostal port facilitates easy gallbladder fossa dissection.

\section{Acknowledgements}

This study has not been funded by any financial organisation or institution.

We have not received any financial grants either. We don't have any industrial links or affiliations.

\section{REFERENCES}

[1] G. Velimezis, J. Antoniades, G. Fraggedakis, G. Sisamakis and E. Perrakis, "Situs Inversus Totalis and Laparoscopic Cholecystectomy: Are They Compatible?” Internet Journal of Surgery, Vol. 26, No. 1, 2010, p. 1.

[2] R. Masood, Samiullah, I. A. Chaudhary and Taimur, "Laparoscopic Cholecystectomy for Left Sided Gall Bladder: An Unusual Case," Journal of Ayub Medical College, Abbottabad, Vol. 21, No. 1, 2009, pp. 162-163.

[3] N. Ghosh, A. Roy, S. K. Bhattacharya, S. Mukherjee and M. Saha, "Laparoscopic Cholecystectomy in Situs Inversus, a Modified Approach,” Internet Journal of Surgery, Vol. 19, No. 2, 2009, p. 21.

[4] J. D. Simmons, E. Maxwell and K. D. Vick, "Laparoscopic Cholecystectomy in the Presence of Abdominal Situs Inversus: Does Surgeon Positioning Matter?” American Surgeon, Vol. 75, No. 4, 2009, p. 353.

[5] D. McKay and G. Blake, "Laparoscopic Cholecystectomy in Situs Inversus Totalis: A Case Report,” BMC Surgery, Vol. 5, 2005, p. 5. http://dx.doi.org/10.1186/1471-2482-5-5

[6] I. Pataki, T. G. Soultan and W. Chanis, "Laparoscopic Cholecystectomy in Totalis Situs Inversus for Cholecystitis,” Magyar Sebészet, Vol. 63, No. 1, 2010, pp. 23-25. http://dx.doi.org/10.1556/MaSeb.63.2010.1.4

[7] C. Sandu and M. Toma, "Laparoscopic Cholecystectomy in a Patient with Situs Inversus Totalis,” Chirurgia (Bucur), Vol. 105, No. 5, 2010, pp. 705-707.

[8] N. Patle, O. Tantia, P. Sasmal, S. Khanna and B. Sen, "Laparoscopic Cholecystectomy in Situs Inversus-Our Experience of 6 Cases," Indian Journal of Surgery, Vol. 72, No. 5, 2010, pp. 391-394. 
http://dx.doi.org/10.1007/s12262-010-0159-4

[9] M. Uludag, G. Yetkin and A. Kartal, "Single-Incision Laparoscopic Cholecystectomy in Situs Inversus Totalis," Journal of Society of Laparoscopic Surgeons, Vol. 15, No. 2, 2011, pp. 239-243.

[10] F. M. González Valverde, M. J. Gómez Ramos, M. Méndez Martínez, J. M. Pérez Montesinos, M. E. Tamayo Rodríguez, M. Ruiz Marín and A. A. Marín-Blázquez, "Laparoscopic Cholecystectomy In A Patient With Situs Inversus Totalis,” Acta Gastroenterologica Latinoamericana, Vol. 40, No. 3, 2010, pp. 264-267. (in Spanish)

[11] H. J. Han, S. B. Choi, C. Y. Kim, W. B. Kim, T. J. Song and S. Y. Choi, "Single-Incision Multiport Laparoscopic Cholecystectomy for a Patient With Situs Inversus Totalis: Report of a Case,” Surgery Today, Vol. 41, No. 6, 2011, pp. 877-880. http://dx.doi.org/10.1007/s00595-010-4387-9

[12] A. Weber-Sánchez, C. Bravo-Torreblanca, D. GarteizMartínez, R. Carbó-Romano, F. Vega-Rivera and R. Hernández, "Case Report: Laparoscopic Cholecystectomy and Common Bile Duct Exploration in a 60-Year-Old Patient with Situs Inversus,” Revista de Gastroenterologia de Mexico, Vol. 76, No. 3, 2011, pp. 255-259.

[13] M. Ozsoy, M. F. Haskaraca and A. Terzioglu, "Single Incision Laparoscopic Cholecystectomy (SILS) for a Patient with Situs Inversus Totalis,” BMJ Case Reports, 2011. http://dx.doi.org/10.1136/bcr.08.2011.4581

[14] M. V. de Campos Martins, J. L. Pantaleao Falcao, J. Skinovsky and G. M. de Faria, "Single-Port Cholecystectomy in a Patient with Situs Inversus Totalis Presenting with Cholelithiasis: A Case Report,” Journal of Medical Case Reports, Vol. 6, 2012, p. 96.

[15] H. S. Pahwa, A. Kumar and R. Srivastava, "Laparoscopic Cholecystectomy in Situs Inversus: Points of Technique,” BMJ Case Reports, 2012.

[16] K. Vagholkar, "Laparoscopic Cholecystectomy and Appendicectomy in Situs Inversus Totalis," Journal of Minimal Access Surgery, Vol. 8, No. 2, 2012, p. 65. http://dx.doi.org/10.4103/0972-9941.95542 